\title{
Cake or death? Ending confusions about asymmetries between consent and refusal
}

\author{
Rob Lawlor
}

\begin{abstract}
Correspondence to Dr Rob Lawlor, InterDisciplinary Ethics Applied Centre, University of Leeds, Leeds LS2 9JT, UK; r.s.lawlor@leeds.ac.uk
\end{abstract}

Received 30 April 2016 Revised 30 July 2016

Accepted 21 August 2016 Published Online First 16 September 2016

\begin{abstract}
In this paper, I will argue that much of the debate concerning asymmetries between consent and refusal (eg, in a case in which an adolescent is granted a right to consent to treatment, but not a right to refuse treatment) is confused. My aim in this paper is to highlight nuances and ambiguities, and to emphasise the fact that we are not just addressing a puzzle about one asymmetry between consent and refusal. I will show that there are a number of relevant asymmetries, not just the asymmetry of competence. And even if we focus specifically on the asymmetry of competence, we need to recognise that 'asymmetry of competence' is ambiguous. By clarifying these issues, my aim is to end the confusion that is common in this debate, allowing us to make progress on an issue that has previously been considered puzzling.
\end{abstract}

\section{INTRODUCTION}

Neil Manson ${ }^{1}$ emphasises that, 'In many jurisdictions adolescents have a right to consent to their own clinical treatment but not a correlative right to always be able to refuse it'. Thus, there are asymmetries between consent and refusal. To many, this is puzzling, incoherent or even nonsense. For example, John Harris writes:

The idea that a child (or anyone) might competently consent to a treatment but not be competent to refuse it is palpable nonsense. ${ }^{2}$

Others, however, have tried to justify these asymmetries between consent and refusal. ${ }^{3}$ However, this is a debate in which there is much confusion. For example, in Ambiguities and Asymmetries in Consent and Refusal: Reply to Manson, ${ }^{4}$ I highlighted some of these confusions in relation to one particular attempt to solve the puzzle. In this paper, however, my aim is not to focus on any particular author, or to reject any particular argument. Rather, my aim is to highlight the ambiguities that seem to lead to widespread confusion within the debate, and to highlight nuances that are lacking from the debate.

My aim in this paper is to highlight nuances and ambiguities, and to emphasise the fact that we are not just talking about a puzzle about one asymmetry between consent and refusal. I will show that there are a number of relevant asymmetries, not just the asymmetry of competence. And even if we focus specifically on the asymmetry of competence, we need to recognise that 'asymmetry of competence' is ambiguous, and there are, in fact, two asymmetries of competence. By clarifying these issues, my aim is to end the confusion that is common in this debate.
In the 'Degrees of competence' section, I defend a scalar view of competence that claims that competence comes in degrees. In the 'Two asymmetries of competence and Wilks' risk-related standard' section, I highlight the significance of this claim, suggesting that it means that there are two asymmetries of competence, not just one. In this section, I also introduce Wilks' idea of a risk-related standard of competence. In the 'Defending Wilks on the possibility of an asymmetry of competence' section, I defend Wilks' risk-related standard and defend his argument that there can be an asymmetry of competence between consent and refusal. In the 'Further ambiguities' section, I argue that the ambiguity between two different types of asymmetry of competence is not the only ambiguity. Ultimately, I argue that there are at least six ways of understanding the claim that there is an asymmetry between consent and refusal, and I explain how people's failure to make these distinctions has led to confusion in the debate about asymmetries between consent and refusal. In the 'Medical ethics and realistic cases' section, I divide real-life healthcare cases into two different types, and I explain the implications of my arguments for each of the two cases. Finally, in the 'Is there a real distinction between asymmetries 2 and 6 ?' section, I reject Wilks' claim that there is no real difference between assessing less carefully whether someone meets a standard on the one hand and actually lowering the standard on the other hand. On the contrary, I argue that the distinction between these two asymmetries is crucial.

As stated in the first paragraph of this paper, the asymmetries between consent and refusal can be found in the law, with adolescents often having a right to consent to treatment but not always a right to refuse treatment. Indeed, Harris was responding to a particular legal case (the case of Re W) when he claimed that the idea of an asymmetry between consent and refusal was 'palpable nonsense'. As I am not an expert in medical law, this paper will focus primarily on the arguments as they apply to ethics. However, these arguments will clearly have implications for the law as well as for ethics, and I do discuss asymmetries of legal rights later in the paper.

\section{DEGREES OF COMPETENCE}

Before going any further, I should acknowledge explicitly that many of my arguments rely on the premise that competence comes in degrees. One reviewer of this paper expressed concern about this, suggesting that it could be a problem for my paper if it does rely on this premise, as this premise is likely to be considered implausible by some readers, and because competence 'has traditionally 
been regarded as a threshold concept', and that this is 'what makes it a useful validating marker for either allowing or disallowing a particular legal status (such as decision making power)'.

First, simply consider ordinary language. We can talk of degrees of competence in a way that we cannot, for example, talk of degrees of two-leggedness. The more I practise the guitar, the more competent I become. 'Competent', unlike 'twolegged', is a gradable adjective. ${ }^{5}$

Second, if the claim is that competence is a threshold concept, we have to ask, what is the threshold a threshold of? Some might answer that it is a threshold of 'understanding' or of 'reasoning abilities'. But each of these, individually, is only one of the constituent parts. So, it seems the threshold is a threshold of all of those things put together. But what is the concept to which those individual parts are the constituent parts. I suggest that the answer is, and can only be, competence. So, the threshold we want-competence-is a threshold on the scale of competence.

When we set the threshold, we are saying this is how competent you need to be in order to be considered a competent person, or this is how competent you need to be to make this particular decision.

More generally, how can we have a threshold on a concept that does not allow for degrees? If a quality does not come in degrees, there is no need for a threshold. It is not necessary, and the idea is incoherent: we cannot set a threshold on twoleggedness. You either have two legs or you do not. In contrast, if we want to divide people into the tall and the not-tall, we have to set a threshold.

Therefore, if you insist that competence is a threshold concept, this does not give us reason to reject the claim that competence comes in degrees. On the contrary, any talk of thresholds implies a scale. The threshold account is not an alternative to the scalar theory of competence. The threshold account relies on a scale. ${ }^{6}$ Daniel Wikler ${ }^{7}$ suggests that competence could be a threshold concept, where the scale that it relies on is a scale of intelligence. But, this ignores the point I make above, that intelligence is only one of the relevant constituent parts.

Finally, this paper itself can be considered a further argument in defence of the claim that we should accept that there can be degrees of competence. If the arguments presented in this paper are successful, and can highlight confusions and suggest a better way forward, then we have reason to favour my approach over others. If there is reason to favour my approach over others, and if the claim that competence can come in degrees is a key part of my approach, this itself is something that counts in favour of this view of competence.

\section{TWO ASYMMETRIES OF COMPETENCE AND WILKS' RISK-RELATED STANDARD}

Once we recognise that competence can come in degrees, we can recognise that there is not just one asymmetry of competence: there are two. I will argue that it is important to recognise this if we are to appreciate the force of Ian Wilks' arguments.

Wilks argues that we can justify the asymmetry of competence between consent and refusal by appealing to two ideas: the idea of a sliding scale theory of competence and the idea of a risk-related standard. $^{8} 9$

The sliding scale theory of competence claims that competence comes in degrees, such that there is a scale of competence, rather than just a binary distinction. This is, essentially, the view that I defended in the previous section.

The second idea is that the level of competence that is required to make a particular decision is related to the riskiness of the decision. The idea then is that, if refusing treatment involves a greater risk than consenting to treatment, one may be competent to consent, but not to refuse-and this is because there will be different standards in each case.

My claim is that, to understand Wilks' argument properly, we must recognise that talk of an 'asymmetry of competence' is ambiguous. We can interpret the 'asymmetry of competence' in two ways, one which focuses on the degree to which someone is competent, and another which focuses on the standard (the threshold understanding of competence).

1. The asymmetry of degrees of competence, between consent and refusal.

This asymmetry would suggest that someone could be competent to a certain degree to consent to treatment, but then be less competent to refuse that same treatment. Wilks does not defend this asymmetry, and neither do I (and I do not know of anyone who does defend this asymmetry).

2. The asymmetry of standards of competence, between consent and refusal.

According to this asymmetry, someone could be competent enough to consent to treatment, but not competent enough to refuse treatment. On Wilks' view, this asymmetry can be justified, because it is appropriate to set the standard higher in one case than another because of the different risks. I will argue that Wilks is right to defend this view, but I will later argue that this conclusion is not as significant as Wilks thinks it is.

The problem is that many of Wilks' critics have not recognised the ambiguity and have not been careful enough to distinguish between the two accounts above. This is significant, because many of Wilks' critics challenge Wilks by presenting arguments that challenge the first asymmetry, suggesting that these arguments refute Wilks' view. As stated above, though, Wilks never defended this asymmetry.

For example, Manson writes:

[A]s Culver and Gert note, the task of comprehending, and deciding for or against treatment, is symmetrical with regard to consent or refusal... ${ }^{10}$

And he concludes:

A person who is competent to reach a decision in favour of a decision to do $\mathrm{X}$ must also be competent to reach a decision not to do X. ${ }^{10}$

This conclusion is most naturally read as a statement about asymmetry 2: it is talking about competence as a threshold-the patient is competent to consent, or he is not. The problem is for the claim that comes before, which presumably is meant to lead to the conclusion, is more naturally read as a statement rejecting asymmetry 1 . Comprehension comes in degrees. Therefore, if the claim is that comprehension is symmetrical with regard to consent or refusal, the claim seems to be that if someone is competent to a certain degree to consent to treatment, then they must be competent, to the very same degree, to refuse that same treatment.

Some might claim that Manson does not believe in a scalar account of competence; so, it is not reasonable to interpret Manson's claim as a claim about asymmetry 1 . It is worth noting, however, that the argument refers to the tasks of comprehending and deciding (the constitutive parts of competence). 
As far as I am aware, Manson has not argued that comprehension and decision-making skills cannot come in degrees.

This is why it is important to emphasise the fact that Wilks does not defend the first asymmetry. He does not need to reject the claim that the tasks of comprehending and deciding are symmetrical with regard to consent or refusal. Wilks only needs to resist the second part, arguing that someone can be considered competent enough to decide in favour of $\mathrm{x}$ even if they are not competent enough to decide not to do $\mathrm{x}$. He does this by appealing to the idea of a risk-related standard.

In the following section, I will defend Wilks' arguments regarding the idea of risk-related standards.

\section{DEFENDING WILKS ON THE POSSIBILITY OF AN ASYMMETRY OF COMPETENCE}

Here, it is crucial to recognise that there are two distinct questions we can ask about a particular decision someone might have to make:

1. How difficult is the decision?

2. How significant are the consequences of the decision?

In addition, we should also recognise that there are two questions we can ask about the competence of the agent: one focusing on degrees of competence, and one focusing on the standard that we use when judging whether a person is suffciently competent:

3. How competent is the person?

4. Is the agent competent enough to make this decision?

At this point, some may complain that, while they can see how question (3) relates to question (1), it is less clear how question (2) fits here. Indeed, one reviewer suggested that 'many would argue that competence to make a decision should have nothing whatsoever to do with how significant the consequences of the decision are'. This is, of course, true. But even if you insist that (2) should not be considered relevant, you must understand that Wilks believes that question (2) is relevant. Anyone who fails to make these distinctions, but who rejects Wilks' argument, cannot be interpreting Wilks correctly or charitably, because Wilks' arguments do not make sense without these distinctions and without focusing on question (2).

This is not to say that Wilks' opponents have to accept Wilks' claims about the significance of each of these questions. However, one does have to recognise- and be alert to- the fact that questions (1) and (2) are different questions, and likewise with questions (3) and (4).

Furthermore, the main aim of this section is to defend Wilks' claim that question (2) is significant and needs to be considered. If it is not yet obvious how question (2) relates to question (4), I can only say that I will be aiming to highlight the relevance in what follows. Crucial arguments here are the cake-or-death argument and my modified version of Wilks' acrobat argument, both of which are presented below.

Wilks defends the asymmetry of competence by appealing to the example of an acrobat. On the face of it, and contrary to the risk-related standard, we might think that if someone is competent to walk a tightrope with a safety net, they are competent to walk the tightrope without a net. ${ }^{11}$ Wilks, however, challenges this:

I suggest that an acrobat of middling reliability might be foolhardy to walk the line without a safety net strung below, while there might be nothing untoward in their attempting it with net in place; and I see it as entirely in accordance with correct usage to describe this as a case where the acrobat is competent to walk the line in the second instance but not in the first. ${ }^{12}$
Manson argues that this argument is flawed in two ways. First, Manson argues that we need to recognise that there is a difference between a person's competence to perform the task (tightrope-walking) and a person's competence to decide to perform the task. Second, we might worry that, in the acrobat example, we are considering a person's competence in relation to two different tasks, rather than focusing on a person's competence in relation to two options within a single decision.

I am not convinced that the first problem is significant. Wilks is not concerned at all with the acrobat's decision-making competence in this case. This can be demonstrated by stipulating first that the acrobat has a very high degree of decision-making competence. Even if we judge him/her to be competent (as a decision-maker), such that we let him/her make his/her own decisions, we can still comment on whether we think he/she is making a sensible decision or not (as Manson himself acknowledges).

Wilks is talking about an acrobat with only a moderate degree of tightrope-walking competence. For this individual, because of the different risks, and given his/her level of tightrope-walking competence, we are likely to judge him/her to be foolhardy if he/she walks the rope with no safety net, but we would not think it foolhardy if he/she chose to walk the rope with a safety net.

Manson writes:

It may be that we think that the acrobat shouldn't walk the dangerous wire; it may be that she is 'foolhardy' to do so... but that does not mean that the novice tightrope walker is not competent to decide to walk without a net. ${ }^{13}$

I agree. As I have argued though, Wilks is not talking about decision-making competence in this example, and everything that Wilks says is consistent with Manson's comment above. Now though, we may have a different worry: if this is an argument relating to tightrope-walking competence, rather than decision-making competence, how does it relate to decisionmaking and healthcare? I suggest that Wilks' argument is relevant because decision-making is not relevantly different from other tasks. In decision-making, just as in acrobatics, there can be two variables involved: (1) how difficult the decision is and (2) how risky or significant the decision is. If this is true, Wilks' argument applies to decision-making as much as it applies to acrobatics.

The second objection, however, seems more significant. As we have seen, those who challenge Wilks do so by insisting that, if we are considering two options available to one person making a single decision, competence must be symmetrical. Therefore, it is legitimate to worry that an example that focuses on a person's competence to perform two different actions will not be analogous to the case we are considering.

To offer an argument that avoids this suspicion, we need an example that focuses on just one decision. In fact, to be as persuasive as possible, the ideal example would avoid both of Manson's objections. We need an example that focuses on decision-making, rather than some physical task like tightrope walking, and we need an example that focuses on a single decision, with just two options.

I suggest that we can find such an example in Eddie Izzard's comedy routine, contrasting the Spanish Inquisition with the Church of England. Before I explain the example and the role it plays in my argument, let me address a more general concern. If I have to resort to an outlandish example, with no basis in reality, and taken from a comedy routine, does this indicate a problem? Does it indicate, for example, that there are no 
real-life cases that I could use to illustrate my point? And, does it indicate that my view is not relevant to real-life cases? I will respond with a general observation and then with a more specific point about the particular case.

There is a reason why philosophers often construct bizarre unrealistic cases rather than appealing to real-life cases, and it is the same reason scientists construct lab experiments, rather than relying on observations about the real world. Crudely, the real world is messy. More technically, scientists want to create artificial conditions in which there is only one variable-whatever it is that they are trying to study-while everything else is kept constant. This can be done in lab experiments in a way that is not possible in the real world. Philosophers construct abstract thought experiments for the same reason: to focus only on the particular details they want to highlight, removing other complications and variables. The result is often that philosophers' examples can seem bizarre and may be written off by some as being unrealistic. But, they are not meant to be realistic any more than lab experiments are meant to be a realistic representation of the real world. The aim is to learn something about something quite specific. In this case, Izzard's bizarre example happens to be a perfect thought experiment to highlight the relevance of both questions (1) and (2): how difficult is the decision and how significant are the consequences of the decision?

I may have been able to consider real-life cases to make the same point. The problem is that many of the real-life cases would be controversial in a way in which Izzard's example is not. Izzard's example is powerful, because it makes the strongest case possible for the claim I will be defending. More realistic cases will be considered in the 'Medical ethics and realistic cases' section.

Izzard imagines an interrogation by the Spanish Inquisition. Threatening to kill the person unless they talk, the interrogator gives the person the following choice: 'talk or die!' Izzard then imagines what the Church of England's inquisition would look like, suggesting that the choice would be: 'cake or death?'

Because, you know, cake or death? That's a pretty easy question. Anyone can answer that.

Cake or death?!

Err, cake please.

Very well! Give him cake.

Oh, thanks very much. It's very nice. ${ }^{14}$

In this example, the decision is not difficult at all. However, the consequences of getting the question wrong-of choosing death by mistake-are very significant. But luckily, such a mistake is very unlikely. However, because the significance of one choice (death) is much greater than the significance of the other choice, there is nothing incoherent about having different standards in each case, such that we require a higher level of competence in order to consider someone competent enough to choose death and a lower level of competence to choose cake. If I offer a person the choice of cake or death, ${ }^{15}$ the person can meet the standard that is appropriate to be considered competent enough to choose cake, even if they do not meet the standard appropriate to be competent enough to choose death.

Consider the tightrope example again, but now consider a third way to walk the tightrope: the rope is set up just inches above the ground. In this case, even the least competent tightrope walker-a complete beginner-is competent enough to attempt tightrope walking, without this being foolhardy. Why?
Because there is little or no risk involved. So, we set the standard of tightrope-walking competence very low. Likewise, we have good reason to set the standard of competence very low for those who choose cake. In contrast, we have good reason to require a higher standard of competence in cases in which a person wants to choose 'death'. (I will return to this argument in the 'Is there a real distinction between asymmetries 2 and 6?' section.)

\section{FURTHER AMBIGUITIES}

However, two points need to be emphasised here. First, this paper is not intended to be a defence of Wilks. I will argue against Wilks later in this paper. Second, the arguments above are not sufficient to end the confusion.

The more significant confusions, where it really seems that people are talking past each other, come when we move from asymmetries of competence to other asymmetries between consent and refusal-for example, when we consider questions about what medical professionals ought to do, or questions about the law, considering what rights we should grant. ${ }^{16}$ This is where the additional ambiguities come to the fore: what do we mean when we talk about an asymmetry between consent and refusal? Which asymmetry do we have in mind? And which asymmetries are important?

It may be natural to think that, if we can defend the asymmetry of competence, other asymmetries should follow, uncontroversially. However, I will argue that this is not the case. I will argue that we need to assess each asymmetry individually, and we need to consider the significance of each asymmetry individually.

At this point, we can identify at least six asymmetries. First, we have the two asymmetries of competence, which we have already identified and discussed:

1. The asymmetry of degrees of competence, between consent and refusal.

2. The asymmetry of standards of competence, between consent and refusal.

And now, we can add four more:

3. The asymmetry of choice, between consent and refusal.

In contrast to 2 above, I suggest that this asymmetry is incoherent. If I offer a person two options, to consent to treatment or to refuse treatment, but I do not allow the person to choose the latter option, I cannot claim that the person had a choice. (More on this below).

4. The asymmetry of permissibility, between consent and refusal.

If a person has to choose between consenting to treatment and refusing treatment, it is coherent to claim that the person should be permitted to choose for themselves, if they consent, but should not be permitted to choose for themselves if they refuse treatment. Of course, some might complain that this would involve deception: when we ask the patient if they consent or not, we are implying they have a choice which, in fact, they do not-if we will not allow them to refuse treatment. (Or, if they do have a choice, the choice seems to be, do you want to do this the easy way or the hard way? Do you want to take the medicine willingly or do you want us to force the treatment on you?)

Later, though, I will argue that an asymmetry of permissibility need not always involve deception. In some cases it will, but in others it will not.

5. The asymmetry of legal rights, between consent and refusal. This is very similar to the previous asymmetry, except that it is the law that is permitting the patient to consent, but not 
to refuse, rather than the doctor. Otherwise, however, the issue is similar. The worry here is that the right to consent appears to be nothing more than the right to choose to have the treatment without a struggle, the only alternative being to have the treatment forced on you. Again, though, I will argue that this is not true in every case.

6. The asymmetry in how carefully we test for competence. ${ }^{17}$ This asymmetry is relatively self-explanatory, and I will discuss the significance of it in the next section, arguing that it is this asymmetry that could make asymmetries 4 and 5 justifiable, in some cases.

Once we recognise that there are (at least) six different asymmetries, we can see where some authors have gone wrong. For example, Harris rejects an asymmetry of competence. ${ }^{2}$ However, he is not careful enough to distinguish between 1 and 2 above, and I have argued that it is his inattention to this distinction that leads him to dismiss-incorrectly-the asymmetry of competence as palpable nonsense. Similarly, Culver and Gert also reject the asymmetry, but their arguments really rely on the first interpretation, while it seems that their intended target is the second interpretation (although, like Harris, they do not seem to recognise the distinction).

Even more significantly, once we make these distinctions, we can see that different authors are often talking past each other. ${ }^{18}$ If we assume that there is just one asymmetry between consent and refusal, then it looks like different authors have a range of different views on this one topic and that they are then holding opposing views on the same topic. So, it seems that authors like Harris, Culver and Gert, Wilks and Manson are all arguing with each other. However, if we recognise the distinctions highlighted above, and if we are careful to interpret authors in light of these distinctions, it is not always obvious that they disagree. In some cases, it seems that they are not even discussing the same topic. ${ }^{19}$ Manson, for example, defends an asymmetry, and therefore takes himself to be arguing against Harris. However, the asymmetries that Manson defends are in fact 3, 4 and 5 . He presents his argument claiming that he is defending the view that Harris considers to be nonsense. But, Harris rejects the asymmetry of competence, and in relation to this particular asymmetry, Manson actually agrees with Harris. The fact that Manson's defence of an asymmetry is consistent with Harris' rejection of the asymmetry of competence is clear from the fact that Manson states explicitly that he has 'explained the asymmetry without making appeal to competence ${ }^{20}$ If that is true, it cannot be the asymmetry of competence that he is defending. Similarly, there is another detail that suggests that Manson agrees with Harris: Manson endorses Culver and Gert's claim that 'the task of comprehending, and deciding for or against treatment, is symmetrical with regard to consent or refusal'. ${ }^{10}$

I have argued that the distinction between asymmetries 1 and 2 is an essential part of Wilks' account. Therefore, he seems to do better than others in terms of recognising the distinction between the first two asymmetries. However, in response to Gita Cale, Wilks explicitly rejects the distinction between 6 and 2 , insisting that it is 'not a real one.. ${ }^{21}$ This last claim is significant because many people will consider asymmetry 6 to be uncontroversial. (I would be very surprised, eg, if Harris considered this asymmetry to be 'palpable nonsense'-and the arguments that Harris, Culver and Gert use to argue against an asymmetry of competence do not challenge asymmetry 6). Therefore, if Wilks is wrong to reject the distinction between 2 and 6, this has significant implications (which I discuss in the 'Is there a real distinction between asymmetries 2 and 6?' section).
If many of the authors writing on this topic are not able to recognise that they are often discussing different topics, and therefore talking past each other, it is not clear that we should be optimistic about making progress in this area. In contrast, if we are careful to keep these different asymmetries distinct, and to make sure we are clear about which we are rejecting and which we are defending, I suggest that we can end the confusion and make better progress.

\section{MEDICAL ETHICS AND REALISTIC CASES}

At this point, we can move to the substantial questions about what medical professional should actually $d o$. I will argue that this will depend, to a large extent, on the type of case.

A. Levels of competence have been established

First, consider a case in which we have already established the level of competence. If we are focusing on degrees of competence, there must be symmetry between consent and refusal. Nevertheless, I also argued that when we come to consider the standard of competence, we can justify an asymmetry.

Ultimately, though, in the cases we are concerned with here, these judgements about asymmetries relating to competence are not important. If we have already established a person's level of competence, the more important asymmetries to consider are 3 , the asymmetry of choice, and 4 , the asymmetry of permissibility.

It is here that we do find a view that can be described as palpable nonsense. There cannot be an asymmetry of choice. To clarify this, my claim is not that this would be morally impermissible. My claim is that it is not possible. If there are only two options, but one option is not actually available, it simply is not true that the patient has a choice.

Moving to asymmetry 4, if we consider the question of whether or not it is permissible to offer the choice (knowing that we would permit the patient to consent to treatment, but would not permit the patient to refuse), we are effectively asking whether it would be permissible for the medical professional to lie and to deceive the patient. Therefore, even if Wilks can defend an asymmetry of competence, it is not clear that this is significant (in this case). Even if we can justify the asymmetry of competence, this will not be enough to justify an approach that allows a patient to consent, but does not allow them to refuse. The asymmetry of choice is incoherent, and (in this case) the asymmetry of permissibility would involve deception.

In other cases, however, things are different.

B. Levels of competence have not been established

In contrast, consider cases in which we have not already established how competent a person is. For example, Wilks imagines a case in which a 76-year-old patient is in hospital, and the nurse offers him treatment. Wilks states that if the patient accepts the treatment, there will be no special effort made to assess his competence. On the other hand, if he refuses the treatment, the doctors and nurses are likely to go to great lengths to test his competence and to decide whether he should be considered competent to refuse treatment.

This type of case is significantly different from the case above. In this case, we do not need to deceive the patient in order to allow a patient to choose to consent to treatment, even if we know that procedures will be quite different if the patient refuses treatment. We can even let the patient know, explicitly, that if they consent, we will give them the treatment, but if they refuse, we might have to consider their competence in more detail, and do more to establish their level of competence, and to consider whether their level of competence is sufficient to 
allow them to refuse treatment. This highlights the significance of the sixth asymmetry: the asymmetry in how carefully we test for competence.

In addition to this asymmetry, we can also justify an asymmetry of permissibility here. If my patient consents to treatment, it is permissible for me to honour their decision, without any further testing of their competence, but if they refuse treatment, it will not be permissible for me to honour their decision, until I have tested their competence more thoroughly. The fact that my response will be different in either case means there is an asymmetry here, between consent and refusal. Similarly, the same argument also applies to asymmetry 5: an asymmetry of rights.

These asymmetries are clearly coherent and do not involve deception in this sort of case.

\section{IS THERE A REAL DISTINCTION BETWEEN ASYMMETRIES 2 AND 6?}

As stated above, Wilks claims that there is no real difference between asymmetries 2 and 6 , because there is no difference between assessing less carefully whether someone meets a standard on the one hand and actually lowering the standard on the other hand. He writes:

If we do not assess very closely how people meet a standard it becomes much easier for them to get by without actually meeting the standard-which is in effect exactly the same as holding them to a lower standard. If I set an easier exam in a course I am not just assessing less carefully whether students meet a given standard: I am actually lowering the standard that they need to meet in order to receive a particular grade. ${ }^{21}$

Again, the cake or death example can help to clarify the issue. Imagine there is an individual I do not know, and therefore I do not know if he is competent or not. I offer the two options, 'cake or death?' If he says 'cake', I have no reason to suspect that he may have misheard or misunderstood. Furthermore, little harm is done, even if I find out later that the person was not competent.

In contrast, imagine that he replies 'death'. In this case, I should probably check he understood before I take my gun out and shoot him.

Did you say 'death'?

Yes, please.

Do you know what death is?

No. But I try to lose weight, and I like try new things. Death less fattening than cake? No?

Even if we agree with Wilks and think that we should set the bar lower for non-risky decisions-such as choosing cake-this man simply does not understand the question. English is not his first language and, obviously, he has not learnt the word 'death' yet. Even if we have a risk-related account of competence, and even if he had chosen 'cake' rather than 'death', we cannot plausibly claim that someone is competent to make a decision if they do not even understand the question. Even if we have a risk-related standard, we cannot set the standard so low that we would deem the person to be competent if they do not even understand the question (regardless of the choice they actually make).

Nevertheless, I do think it is permissible to give this person cake. This is not because they have shown themselves to be competent enough to make this particular decision. Rather, it is because it does not actually matter if it turns out that he was not competent.

Focusing on the more realistic cases, there is also another reason to reject Wilks' claim that there is no real difference between setting the standard lower and checking less carefully whether the standard is met or not, which was highlighted in the previous section, in which I argued that it makes a big difference whether levels of competence have already been assessed or not.

If we appeal to an asymmetry of standards of competence (asymmetry 2) in order to defend an asymmetry of choice, we have a problem. As I argued above, an asymmetry of choice is incoherent. Thus, I argued, we could only defend an asymmetry of permissibility if we were willing to deceive the patient (to try to persuade them that they have a choice, when actually they do not). In contrast, in cases where levels of competence have not yet been established, I appealed to asymmetry 6 in order to defend the asymmetry of permissibility and the asymmetry of legal rights, arguing that-if we appeal to asymmetry 6-there is no incoherence and no need for deception. This argument only works because of the features that are found in asymmetry 6, which are not found in asymmetry 2 . This then is a real-and very significant-difference between the two asymmetries.

\section{CONCLUSION}

In summary, I have argued that authors typically do not make enough of an effort to distinguish between different asymmetries between consent and refusal, and to make it clear what they are claiming and what they are denying. Once we clarify the numerous different ways in which there can be an asymmetry between consent and refusal, and recognise that some are incoherent and some are not, and recognise that some involve deception but some do not, we can end the confusion surrounding asymmetries between consent and refusal, and we can make more progress in these debates.

More specifically, I have argued for the following claims:

- If we recognise that competence can come in degrees (as well as being used as a threshold concept), and if we recognise the ambiguity between different interpretations of an asymmetry of competence (thus distinguishing between asymmetries 1 and 2), we can see that Harris is mistaken to consider asymmetry 2 to be palpable nonsense.

- Although the appeal to risk-related standards helps to identify the problems with Harris' objection, and allows us to defend an asymmetry of competence, this does not make a significant difference in cases where we already know how competent a person is. This is because asymmetry 3 remains incoherent, and asymmetries 4 and 5 involve deception (in these cases).

- In cases in which we have not yet assessed a patient's competence, asymmetries 4 and 5 do not involve deception, and can therefore be justified. However, they need to be justified by appeal to asymmetry 6 .

Acknowledgements To a large extent this paper was written alongside my earlier paper, Ambiguities and Asymmetries in Consent and Refusal: Reply to Manson. Therefore, I am grateful to Neil Manson for his comments on early drafts of that paper. In addition, I am grateful to Elizabeth Ellis for comments on an earlier draft of this paper, and I am also grateful to two anonymous referees for very helpful comments on the first submitted version of this paper.

Competing interests None declared.

Provenance and peer review Not commissioned; externally peer reviewed. 


\section{REFERENCES}

1 Manson N. Transitional paternalism: how shared normative powers give rise to the asymmetry of adolescent consent and refusal. Bioethics 2014;29:66.

2 Harris J. Consent and end of life decisions. J Med Ethics 2003;29:10-15.

3 To give just two examples, Manson N. Transitional paternalism: how shared normative powers give rise to the asymmetry of adolescent consent and refusal. Bioethics 2014;29, and Wilks I. Asymmetrical competence. Bioethics 1999;13.

4 Lawlor R. Ambiguities and asymmetries in consent and refusal: Reply to Manson. Bioethics 2016;30:353-7.

5 See Klein E. Comparatives. In: von Stechow A, Wunderlich D, eds. Semantics: an international handbook of contemporary research. Berlin: De Gruyter, 1991:673-91. Also, I talk about 'competent' as a gradable adjective in more detail in Gradable Competence: a challenge to liberals and a defence of paternalism (work in progress).

6 My views on competence, and degrees of competence, are discussed in more detail in Gradable Competence: a challenge to liberals and a defence of paternalism (work in progress). My views of the relation between scalar concepts and thresholds in relation to ethics more generally are discussed in much more detail in Shades of Goodness: Gradability, Demandingness and the Structure of Moral Theories. New York: Palgrave Macmillan, 2009.

7 Wikler D. Paternalism and the Mildly Retarded. Philos Public Aff 1979:8:377-92.

8 Wilks I. Asymmetrical competence. Bioethics 1999;13:154-9.

9 Wilks I. The debate over risk-related standards of competence. Bioethics 1997;11:413-26.

10 Manson N. Transitional paternalism: how shared normative powers give rise to the asymmetry of adolescent consent and refusal. Bioethics 2014;29:68. Also see Culver CM, Gert B. The inadequacy of incompetence. Milbank Q 1990; 68:620.

11 Plausibly, there may be a complication here, in that the fear of falling may upset an individual's concentration, such that they actually are more likely to fall. For the sake of argument, however, imagine this is not the case for this particular acrobat. He has great control of his fear. His weakness is in the basic technique, such that —for him — the difficulty of walking the rope without a net is no different from walking the rope with the net. It is natural, therefore, to think that if he is competent to walk one rope, he is competent to walk the other.

12 Wilks I. Asymmetrical competence. Bioethics 1999;13:156.

13 Manson N. Transitional paternalism: how shared normative powers give rise to the asymmetry of adolescent consent and refusal. Bioethics 2014;29:68-9.

14 Eddie Izzard: Dress to Kill, dir. by Lawrence Jordan (Universal Pictures UK, 2004). Also see https://www.youtube.com/watch?v=rMMHUzm22oE (accessed 10 April 2016).

15 Here, and in the following examples, cake or death are the only two options. Refusing both is not an option. (If it was, this would be a third option.) To make this case relevantly similar to the consent or refusal case, it is important that it is a choice with only two options.

16 Consider the first quote (from Manson) in the opening sentence of this paper, about different rights in different jurisdictions.

17 Gita Cale makes this distinction in his paper Cale G. Continuing the debate over risk-related standards of competence. Bioethics 1999;13:131-48 (p. 148). And Wilks responds by rejecting the distinction in Wilks I. Asymmetrical Competence. Bioethics 1999;13:155. In this paper, I will not try to resolve this dispute. I will simply highlight that we can make this distinction-and it is an open question whether we should consider the distinction to be significant or not. This is a question I will leave for a later paper.

18 For a more detailed discussion of particular authors talking past each other, and indeed failing to recognise that they actually agree on the question of the asymmetry of competence, see Lawlor, R. Ambiguities and Asymmetries in Consent and Refusal: Reply to Manson. Bioethics, 2016;30:353-7.

19 I discuss some of these issues in more detail in Ambiguities and Asymmetries in Consent and Refusal: Reply to Manson. Bioethics, 2016:30:353-7.

20 Manson N. Transitional paternalism: how shared normative powers give rise to the asymmetry of adolescent consent and refusal. Bioethics 2014;29:71.

21 Wilks I. Asymmetrical competence. Bioethics 1999;13:155. My italics and underlining - the purpose of which is explained in what follows. 